2. Koval, I. S. \& Burak, O. B. (2013). Formuvannia osobystosti maibutnoho fakhivtsia $\mathrm{v}$ umovakh navchalnoho protsesu [Formation of the personality of the future specialist in the conditions of the educational process]. Osobystist $v$ ekstremalnykh umovakh: $z b$. tez VI Vseukr. nauk.-prakt. konf. z mizhnar. uchastiu; 7-8.11. $2013 r$. - Personality in extreme conditions: Collection of theses of the VI All-Ukrainian Scientific-Practical Conference with international participation. 7-8.11. 2013, (pp.211-213). Lviv. [in Ukrainian].

3. Melnyk, I. (2012). Kharakterystyka profesiinoi kultury spilkuvannia maibutnikh fakhivtsiv pozhezhnoi bezpeky [Characteristics of the professional culture of communication of future fire safety specialists]. Journal of the Uman State Pedagogical University. Vol. 3, pp. 208 -215. [in Ukrainian].
4. Sadkovyi, V. \& Horoneskul, M. (2016). Osoblyvosti profesiinoi pidhotovky maibutnikh fakhivtsiv u sferi tsyvilnoho zakhystu [Features of professional training of future specialists in the field of civil protection]. Journal of the New Collegium. Vol. 3, pp. 18 -22. [in Ukrainian].

5. Filshtein, L. M. \& Zhuravlov, V. M. (2016). Profesiina kultura $\mathrm{v}$ aspekti pidhotovky fakhivtsiv [Professional culture in the aspect of training specialists]. Journal of the Kirovohrad National Technical University. Vol. 29, pp. 12-18. [in Ukrainian].

6. Tsybulko, I. O. (2013). Osoblyvosti profesiinopsykholohichnoi kultury fakhivtsiv tsyvilnoi aviatsii [Features of the professional-psychological culture of civil aviation specialists]. Journal of the National Academy of the State Border Guard Service of Ukraine. Vol. 3. [Electronic resource]. Available at:http:/nbuv.gov.ua/UJRN/Vnadps_2013_3_41. [in Ukrainian].

Стаття надійшла до редакції 29.10.2018

УДК 81’25:811.111:811.161.2

DOI:

Тетяна Ходутіна, студентка 2 курсу ОС “Магістр” Національного університету біоресурсів і природокористування України, м. Київ Лариса Колодіна, кандидат філологічних наук, доиент кафедри романо-германських мов і перекладу

Національного університету біоресурсів і природокористування Украӥни, м. Київ

\title{
ОСНОВНІ ПРИНЦИПИ ПЕРЕКЛАДУ ТЕКСТІВ ОФІЦЙНО-ДІЛОВОГО СТИЛЮ 3 АНГЛІЙСЬКОЇ ТА УКРАЇНСЬКОЇ МОВ
}

У статті проаналізовано спеиифіку перекладу офіиійно-ділового стилю. Визначено основні особливості, які слід враховувати під час перекладу. Охарактеризовано лексичні та граматичні особливості перекладу текстів офіційно-ділового змісту. У процесі дослідження було з'ясовано, щио найголовнішою вимогою перекладу є адекватність. При відсутності відповідників застосовуються лексичні та граматичні трансформації. Дослідження закономірностей перекладу офіційно-ділового стилю дає підстави стверджувати, що цеей стиль є одним із найважчих для перекладу, тому потребує уважності, обізнаності, ерудованості та фонових знань перекладача. Головною вимогою є передача думок та об' єктивності фактів, чітка визначена форма і правильне застосування перекладацьких трансформачій, які є суттєвим компонентом перекладачької компетентності.

Ключові слова: офічійно-діловий стиль; переклад; документ; трансформація; кліше.

Табл. 1.Літ. 7.

Tetyana Khodutina, the II st year Master Student,

National University of Life and Environmental Sciences of Ukraine, Kyiv

Larysa Kolodina, Ph.D.(Philology), Associate Professor of the

Romance and Germanic Languages and Translation Department,

National University of Life and Environmental Sciences of Ukraine, Kyiv

\section{BASIC PRINCIPLES OFTRANSLATION OF OFFICIAL-BUSINESS TEXTS IN ENGLISH AND UKRAINIAN LANGUAGES}

The research consists in determining the specifics of the official-business style translation. The translator must follow the strict rules and proper use of standard language templates, as well as know the features of official business communication, correspondence and business etiquette skills. The translator's actions for creating a translation text are called the translation process. It includes two stages: the study of the translator's content of the original text and the choice of the translation option. As a result of these stages, the transition from the original text to the text of the translation is carried out. The main features that must be taken into account during the translation are the use of vocabulary in the literal sense, the presence of phrases, stable phrases, cliches, words of foreign origin, modal verbs, adjectives, infinitive forms, abbreviations, non-equivalents vocabulary. The most important translation 


\section{ОСНОВНІПРИНЦИПИПЕРЕКЛАДУ ТЕКСТІВ ОФПЦЙНО-ДІЛОВОГОСТИЛЮ З АНГЛЙСЬКОЇ ТА УКРАЇНСЬКОЇ МОВ}

requirement is adequacy. In case of absence of corresponding words, lexical transformations can be used. The grammatical features of texts of official-business content include standardization, the prevalent use of simple and complex sentences, passive constructions. In the case of a translation from English into Ukrainian, sentences often do not coincide in structure, which may be caused by differences in the order of words, parts of the sentence, time, state and numbers. Therefore, it is necessary to use grammatical transformations. Their use should be aimed at an adequate transmission of the content of the original text taking into account all the rules of translation.

The research of the translation of the official-business style gives reason to confirm that, as one of the most difficult types of translation, it needs a lot of awareness, erudition and background knowledge. The main requirement is to transfer thoughts and objectivity of facts, to define the form clearly and to use translation transformations correctly because they are an essential component of translation competence.

Keywords: official-business style; translation; document; transformation; cliche.

П остановка проблеми. На сьогоднішній день економічний і політичний розвиток суспільства стає все більш інтенсивним. Розвиваються міжнародні економічні зв'язки, з'являються нові технології, розширюються галузі їхнього використання. В умовах швидко зростаючої глобалізації збільшується інтенсивність міжнародних контактів, основною метою яких $\epsilon$ обмін знаннями, досвідом, а також співпраця. Як наслідок виділився функціональний стиль ділової документації та ділового мовлення. Спрямування офіційно-ділового стилю полягає у використанні його у дипломатичній, управлінській діяльності, законодавстві, політиці та багатьох інших сферах людської діяльності.

Аналіз досліджень. Велика кількість науковців приділяли увагу дослідженню різних аспектів офіційно-ділового стилю. Питання, пов'язані із особливостями перекладу текстів офіційно-ділового стилю, висвітлені у працях М. Беляєвого [1], Е. Попової [1], В. Карабана [2], В. Комісарова [3], Л. Граудіної [4], Е. Лазугкіної [5], І. Гальперіного [6], Л. Рахманіна [7].

Мета статті - проаналізувати та узагальнити характерні особливості перекладу англомовних та україномовних текстів офіційно-ділового стилю.

Виклад основного матеріалу. Згідно Л.К. Граудіною, “офіційно-діловий стиль - це сукупність мовних засобів, функція яких - обслуговування сфери офіційно-ділових відносин, які виникають між державними органами, організаціями, їх підрозділами в процесі економічної, господарської, дипломатичної та юридичної діяльності" $[4,131]$. Сфера його функціонування - “адміністративноправова діяльність та відношення між суб'єктами права: державою і громадянами, приватними, юридичними та посадовими особами" [6, 129]. Л.В. Рахманін терміном офіційно-діловий стиль позначає особливості мовлення службових, у першу чергу організаційно-розпорядчих документів [7,37]. Отже, офіційно-діловий стиль - це сукупність мовних засобів, функція яких обслуговування сфери офіційно-ділових відносин, які виникають між органами держави, організаціями та приватними особами під час їхньої діяльності. Між перекладом звичайних текстів та перекладом офіційно-ділового стилю існують суттєві відмінності, які пов'язані із деякими особливостями перекладу ділової документації. Офіційні тексти характеризуються високим ступенем стандартизації, яка стосується ї структури і навіть організації побудови параграфів у ній. Офіційно-діловий стиль, в якому виконана ділова документація, $є$ більш консервативним, і перекладачеві це потрібно враховувати.

Передача інформації в документальному вигляді $є$ особливістю офіційно-ділового стилю. Із його допомогою звичайні відносини між партнерами стають офіційно-діловими. Для цього стилю характерна дуже сувора, навмисно стримана та знеособлена тональність передачі змісту того чи іншого документа. Діловий стиль документації завжди максимально конкретний, із чітким зазначенням інформації, яка включає певну кількість осіб, дат і предметів. При цьому в діловій документації завжди застосовуються стандартні мовні засоби вираження.

Перед тим, як перекладати усний чи письмовий офіційно-діловий дискурс, необхідно звертати увагу на його особливості та ознаки, для того щоб інформацію передати правильно та зрозуміло. До традиційних рис офіційних документів належать:

- традиційність вираження;

- закодована мовна система;

- точні та лаконічні формулювання;

- нейтральний беземоційний фон;

- безособові лексичні конструкції.

Перекладач повинен дотримуватись суворих норм та правильного користування стандартними мовними шаблонами, а також знати особливості офіційно-ділового спілкування, кореспонденції та мати навички ділового етикету. Дії перекладача щодо створення тексту перекладу називаються процесом перекладу. Він включає в себе два етапи: дослідження перекладачем змісту тексту оригіналу і вибір варіанта перекладу. У результаті виконання цих етапів здійснюється перехід від тексту оригіналу до тексту перекладу. Нижче 
наведено головні ознаки офіційно-ділового стилю, які треба враховувати при перекладі вихідного тексту:

- використання слів уїх прямому значенні. Під час перекладу ділової документації тут не повинно бути контекстних значень або їх одночасної реалізаціі;

- фразеологічні поєднання та кліше, які є загальноприйнятими у діловому мовленні, на відміну від розмовного: expenses (витрати); account (рахунок); financial support (фінансова підтримка); the abovementioned (згаданий вище); invoice (рахунок); to draw a close (на завершення...); прохання повідомити нас про...; рекомендую Вам; нам відомо, щзо...; на nідставі; y зв'язку з; у иілях; із метою;

- слова латинського, грецького та французького походження, які зазнають частого використання при перекладі. Неправильний їх переклад може спотворити розуміння документу: persona grata (особа, яка користується довірою), persona non grata (особа, якій не довіряють); рro teтроге (тимчасовии); the quотит (необхідна кількість учасників на засіданні тощьо); conditio sine qua поп (обов'язкова умова); status qио (положення/стан, в якому); mutatis mutandis (з урахуванням відповідних змін);

- використання модальних дієслів, які виражають ввічливість та відношення адресанта, але не позначають конкретний стан (shall, could);

- вживання інфінітиву, дієприкметників та дієслів із закінченням “-ing”. Віддієслівні форми використовуються в комерційній та діловій кореспонденції, а найчастіше вживається інфінітив, який служить доповненням до дієслів, іменників та прикметників. Тому саме він може виконувати функції додатку, підмета, присудка, обставини тощо;
- безеквівалентна лексика, тобто лексика, яка не має відповідників. При їі перекладі постає головне завдання, а саме: досягнення практичної інформаційної еквівалентності перекладу тексту оригіналу;

- наявність скорочень - вони повинні бути розшифрованими і перекладеними за загальноприйнятими правилами: gvt-government (уряд); adv. - advance (кредит); c/a - current account (поточний рахунок);

- co - company (компанія). Також сюди можна віднести абревіатури. Абревіація - це лінгвістичне явище, яке відображає загальні та внутрішні риси, характерні для різних мов, але часто скорочення англійської та української мов, при їх перекладі, можуть співпадати (табл. 1).

Інколи буває, що обсяг лексичних одиниць мови оригіналу та мови перекладу не співпадають, тобто не існує відповідника. Таку відсутність слова називають лакуною. Часто співпадіння $\epsilon$ неповним або різним значенням багатозначного слова в мові оригіналу відповідають різні слова у мові перекладу. Це і є причиною використання лексичних трансформацій.

В.Н. Комісаров стверджує, що “лексичні трансформації описують формальні і змістові зв'язки між словами і словосполученнями в оригіналі та перекладі” [3, 158]. До формальних перетворень він відносить транскрипцію і транслітерацію, а також калькування. Суть транскрипції у тому, що при перекладі відтворюється звучання слова оригіналу. Сюди можна віднести власні назви, імена, географічні назви, назви фірм, термінів тощо. Явище транслітерації полягає навпаки у відтворенні графічної форми. Під калькуванням розуміємо переклад лексичних одиниць шляхом зміни

Переклад абревіатур в англійській та українській мовах

Таблиця 1.

\begin{tabular}{|c|c|c|}
\hline & Українська мова & Англійська мова \\
\hline Міжнародний валютний фонд & МBФ & $\begin{array}{c}\text { IMF (International Finance } \\
\text { Corporation) }\end{array}$ \\
\hline Європейська валютна система & $\mathrm{EBC}$ & $\begin{array}{c}\text { EMC (European Monetary } \\
\text { System) }\end{array}$ \\
\hline Валовий внутрішній продукт & ВВП & GDP (Gross Domestic Product) \\
\hline Податок на додану вартість & ПДВ & VAT (Value Added Tax) \\
\hline $\begin{array}{c}\text { Товариство з обмеженою } \\
\text { відповідальністю }\end{array}$ & TOB & LTD (Limited Liability Company) \\
\hline Європейський Союз & $\mathrm{EC}$ & EU (European Union) \\
\hline
\end{tabular}




\section{ОСНОВНІПРИНЦИПИПЕРЕКЛАДУ ТЕКСТІВ ОФІЦЙНО-ДІЛОВОГОСТИЛЮ ЗАНГЛЙСЬКОЇ ТА УКРАЇНСЬКОЇ МОВ}

складових частин, які утворюють слово або словосполучення, а також об'єднання їх в єдине ціле, але при цьому порядок слів у словосполученні може варіюватись [3, 158 - 159]. До лексико-семантичних замін В.Н. Комісаров відносить конкретизацію, генералізацію, модуляцію, експлікацію, адаптацію, компенсацію та ампліфікацію. Прийом смислової конкретизації полягає в тому, що перекладач під час перекладу слова у мові оригіналу обирає одиницю з більш конкретним значенням у мові перекладу. Ї̈̈ застосування пов'язане 3 тим, що у мові перекладу відсутнє слово 3 таким самим значенням. Генералізація $є$ протилежним поняттям конкретизації - заміни слова, яке має більш вузьке значення у мові оригіналу, на слово із більш широким значенням у мові перекладу. Вона застосовується, коли назва якогось предмету є невідомою для адресата перекладу; коли якийсь предмет у тексті $є$ зайвим в умовах контексту; коли загальне значення із стилістичних причин є більш прийнятним. Модуляцією називається прийом, який полягає у заміні слова або словосполучення мови оригіналу одиницею у мові перекладу, значення якої логічно виводиться iз значення вихідної одиниці. Експлікацією виступає описовий переклад, коли одиниця у мові оригіналу може бути замінена на словосполучення iз поясненням чи визначенням цього значення. Найчастіше використовується при поясненні термінів. При цьому потрібно намагатись надати якнайкоротше визначення, тому що багатослівність $є$ неприпустимою. Адаптація в основному застосовується при перекладі фразеологізмів, сленгу, усталених фраз. Компенсація $є$ передачею втрачених через відсутність у культурі лексичних елементів та їх заміною на інші одиницями. Ампліфікація полягає у заміні скороченої назви у тексті оригіналу на повну у мові перекладу. В основному прийом поширюється на назви різноманітних організацій, місць чи посад. Також до лексичних трансформацій належить антонімічний переклад, коли стверджувальна форма змінюється на заперечну у мові перекладу або навпаки. Лексичні одиниці можуть бути замінені у мові перекладу не лише протилежними, а й такими словами $\mathrm{i}$ словосполученнями, які виражають протилежну думку [3, 159 - 161].

Грамотний переклад неможливий без дотримання граматичних закономірностей, адже граматика спрямована на вивчення форм словозміни, побудови слів, видів словосполучень та типів речень, а також закони зв'язку слів та словосполучень. До граматичних особливостей офіційно-ділового стилю належить уніфікація (стандартизація) граматичної структури словосполучень та словоформ. При всій неоднорідності текстів стилю офіційних документів виділяються деякі риси, які $\epsilon$ спільними для всіх ділових документів. Речення із дієсловом-присудком у пасивному стані також складають певні труднощі під час їх перекладу на українську мову. 3 однієї сторони, форма пасивного стану в англійській мові може бути утворена від перехідних дієслів та дієслів, які потребують певного доповнення до них, наприклад to deal with - мати справу з. 3 іншої сторони, можлива невідповідність граматичної категорії перехідності дієслова. При перекладі англійське перехідне дієслово, яке потребує після себе об'єкта дії в українській мові, може відповідати неперехідному дієслову (to join приєднуватись до). У пасивному стані використані фразеологічні сполучення неможливо перекласти еквівалентами, а тому необхідно замінювати пасивний стан на активний $[1,19-$ 20]. Сюди також належать інфінітивні конструкції is thought (вважається), is expected to (очікується) та інші. Також в англійській мові часто зустрічається явище інверсії, яка використовується у підрядних реченнях умови i порівняння із обмеженою кількістю дієслів руху або для відокремлення прислівників. У таких реченнях частини дієслова-присудка вживаються у зворотному порядку:...should we receive...we would... (...якби ми отримали..., ми б...).

В українській мові, на відміну від англійської, відсутні такі граматичні категорії як герундій, артикль, інфінітивні та прислівникові комплекси. Частковий збіг у значенні і використанні відповідних форм та конструкцій або його відсутність також потребують граматичних трансформацій [5, 230].

За дослідженням В.I. Карабана, граматичні трансформації - це зміна граматичних ознак слова, словосполучення або речення під час перекладу [2, 159 - 165]. Існують такі їх види:

- перестановка (зміна порядку слів у словосполученні або реченні; зміна синтаксичної структури речення, при чому інформативна структура залишається незмінною);

- заміна (зміна ознак словоформ, частин мови, членів речення; найчастіших змін зазнають іменник, прикметник, дієслово та прислівник, також можуть змінюватись граматичний час, пасивний і активний стан, форми однини та множини, членування речень тощо);

- додавання (збільшення кількості слів, словоформ або членів речення; воно відбувається 
через лінгвокультурологічні розбіжності, адже мова оригіналу не має іншомовних прямих відповідників у мові перекладу, томузміни повинні виходити за межі тексту, наприклад, у коментарях чи покликаннях);

- вилучення (вилучення певного мовного елементу; при цьому потрібно дотримуватись необхідного обсягу тексту. Найчастіше вилучаються ті лексичні елементи, без яких не порушиться адекватність тексту, а також синоніми, які є близькі за значенням 3 метою уникнення тавтологіi);

- комплексна трансформація (одночасне застосування двох або більше граматичних трансформацій).

Переклад з однієї мови іншою неможливий без використання перекладацьких трансформацій, які $\epsilon$ своєрідною перебудовою речень, зміною їх структури. У зв'язку із наведеною низкою розбіжностей граматичних форм і конструкцій в англійській та українській мовах вважаємо, що необхідно використовувати саме граматичні трансформації для передачі інформації з однієї мови іншою.

Висновки та перспективи подальших досліджень. Дослідження закономірностей перекладу офіційно-ділового стилю дає підстави стверджувати, що саме цей стиль є одним із найважчих для перекладу, тому потребує неабиякої обізнаності, ерудованості та фонових знань перекладача. Головною вимогою $\epsilon$ передача думок та об'єктивності фактів, чітка визначена форма та правильне застосування перекладацьких трансформацій, які є суттєвим компонентом перекладацької компетентності.

\section{ЛІТЕРАТУРА}

1. Беляев М.А., Попова Е.В., Серова И.А. Грамматические и синтаксические аспекты перевода статей газетной публицистики: Уч. пособие. - СПб.: Изд-во СПбГУ ЭФ, 2010. C. 19-20.

2. Карабан В.I. Теорія і практика перекладу 3 української мови на англійську мову: Посібникдовідник: Навчальний посібник зі спец. "Переклад" / В. І. Карабан, Д. Мейс. - Вінниця: Нова книга, 2003. - С. 159-165.

3. Комиссаров В.Н. Теория перевода (лингвистические аспекты). - М.: Высшая школа, 1990. - C. 158-161.
4. Культура русской речи. Учебник для вузов. Под ред. проф. Л.К. Граудиной и проф. Е.Н. Ширяева. - М.: Издательская группа Норма-Инфра, 1999. - C. 131.

5. Лазуткина Е.М. Культура деловой речи // Культура русской речи. Учебник для вузов. - М.: Издательство "Норма", 2000. - С. 216-237.

6. Радугин А.А. Русский язык и культура речи [Текст]: учебное пособие для высших учебных заведений / А.А. Радугин. - М.: Библионика, 2004. - C. 129.

7. Рахманин Л.В. Стилистика деловой речи и редактирование служебных документов: учебное пособие / Л.В. Рахманин. - М.: Высшая школа, 1988. - C. 37.

\section{REFERENCES}

1. Belyaev, M. A., Popova, E. V. \& Serova, I. A. (2010). Grammaticheskie i sintaksicheskie aspekty perevoda statey gazetnoy publitsistiki [Grammatical and syntactic aspects of translation of newspaper publicism articles]. Tutorial. St. Petersburg: SPbGU EF, pp. 19-20. [in Russian].

2. Graudina, L. K. \& Shiryaev, E. N. (1999). Kultura russkoy rechi [Russian language culture]. University Tutorial. Moscow: Publishing Group "Norma-Infra", p. 131. [in Russian].

3. Karaban, V. I. (2003). Teoriya i praktika perekladu z ukrainskoi movy na angliysku movu [The theory and practice of translating from Ukrainian into English]. Tutorial on specialty "Translation". Vinnytsia: Nova Knyga, pp. 159-165. [in Ukrainian].

4. Komisarov, V. N. (1990). Teoriya perevoda (lingvisticheskie aspekty) [The translation theory (linguistic aspects)]. Moskow: Vysshaya shkola, pp. 158-161. [in Russian].

5. Lazutkina, E. M. (2000). Kultura delovoy rechi [Culture of business speech]. Culture of Russian speech. University Tutorial. Moscow: Publishing House "Norma", pp. 216-237. [in Russian].

6. Radugin, A. A. (2004). Russkiy yazyk i kultura rechi [Russian Language and culture of speech]. University Tutorial. Moscow: Biblionika, p. 129. [in Russian].

7. Rakhmanin, L.V. (1988). Stilistika delovoy rechi $i$ redaktirovanie sluzhebnykh dokumentov [Styling business speech and editing official documents]. Tutorial. Moskow: Vysshaya shkola, p. 37. [in Russian].

Стаття надійшла до редакції 19.10.2018

G5808NC2058080

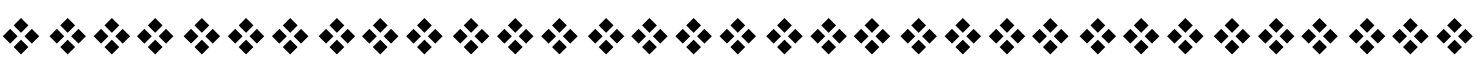

